УДК 547.915.:665.33

DOI: $10.33184 /$ bulletin-bsu-2020.2.7

ЖИРНЫЕ КИСЛОТЫ СЕМЯН NONEA PULLA DC., ПРОИЗРАСТАЮЩЕЙ НА ТЕРРИТОРИИ РФ

\author{
(С) С. Г. Юнусова ${ }^{1 *}$, С. С. Ляшенко ${ }^{2}$ К. В. Ведерникова ${ }^{3}$, \\ Н. И. Федоров ${ }^{4}$, Ю. О. Денисенко ${ }^{2}$, О. Н. Денисенко ${ }^{2}$ \\ ${ }^{l}$ Уфимский институт химии УФИЦ РАН \\ Россия, Республика Башкортостан, 450054 г. Уфа, пр. Октября, 71. \\ ${ }^{2}$ Пятигорский медико-фармацевтический институт \\ филиал Волгоградского государственного медицинского университета Минздрава России \\ Россия, 357532 г. Пятигорск, пр. Калинина, 11. \\ ${ }^{3}$ Крымский федеральный университет им. В. И. Вернадского \\ Медииинская академия им. С.И. Георгиевского \\ Россия, 295051 г. Симферополь, бульвар Ленина, 5/7. \\ ${ }^{4}$ Уфимский институт биологии УФИЦ РАН \\ Россия, Республика Башкортостан, 450054 г. Уфа, пр. Октября, 71. \\ Тел.: +7 (347) 2355839. \\ *Email:msyunusov@anrb.ru
}

\begin{abstract}
Изучен состав жирных кислот (ЖК) трех образиов семян Nonea pulla (сем. Boraginaceаe) разных климатических зон произрастания: I - Крым, степная зона, II - Крым, горная зона и III - Южный Урал. Содержание нейтральных липидов (НЛ) для I, II и III составляет соответственно - 14.8, 15.7 и 15.5\%. В составе ЖК идентифичированы эссенциальные $\omega$ 6, $\omega-3$ ЖК, для I, II и III их суммарное количество равно 61.5, 60.8 и 57.8\%. Для III выделень полярные липиды и триацилглицериды, для которых определен состав ЖК.
\end{abstract}

Ключевые слова: Nonea pulla, Boraginaceае, липиды, жирные кислоты.

Основным классом липидов, отвечающих за биологическую активность, являются жирные кислоты (ЖК). Существует понятие незаменимых (эссенциальных) жирных кислот, которые не синтезируются в организме человека, но необходимы для нормального функционирования клеток. Высшие растения, являются продуцентами $\mathrm{C}_{18}$-полиненасыщенных жирных кислот (ПНЖК) - $\alpha$-линолевой ( $\omega$-6 18:2), $\gamma$-линоленовой ( $\omega-6$ 18:3), $\alpha$-линоленовой ( $\omega-3$ 18:3) и стеаридоновой ( $\omega-3$ 18:4) кислоты, которые как конечные метаболиты, накапливаются в тканях растений. В организме человека являются предшественниками гармоноподобных соединений (простогландины, тромбоксаны, лейкотриены), которые участвуют во многих жизненно важных процессах [1-4].

ПНЖК не синтезируются в организме человека, их отсутствие в повседневном питании может приводить к развитию широкого спектра заболеваний, таких как сердечно-сосудистые, воспалительные процессы, вирусные инфекции, некоторые виды рака и аутоиммунные заболевания [5-9].

Одним из растительных источников ПНЖК являются растения сем. Boraginaceae. Известно, что состав природных соединений, включая липиды, во многом зависит от условий внешней среды и места произрастания. Флора России, и в т.ч. Башкортостана, является богатейшим растительным источником полиненасыщенных жирных кислот, липидный состав которых до сих пор мало изучен.

Nonea pulla (Нонея темно-бурая один из видов рода Нонея, сем. Boraginacea) многолетнее травя- нистое растение, включает около 30 видов, ареалом которого являются страны Средиземноморья, Европы, Средней Азии, Кавказа, Украины, европейской части России (Причерноморский район). На территории России произрастает 3 вида, среди которых наиболее распространена Nonea pulla - лекарственное растение, использующееся в народной медицине для лечения многих заболеваниях [10]. В зарубежной литературе имеются сведения [11-13] об изучении состава ЖК семян Nonea pulla, однако для исследования брались коммерчески доступные семена, происхождение которых не было известно.

В продолжение работ [14-17] по поиску источников ПНЖК среди растений сем. Boraginaceae на территории РФ, определили содержание нейтральных липидов и состав жирных кислот семян вида Nonea pulla из разных мест произрастания на территории РФ.

Исследовали 3 образца семян разных климатических зон произрастания: I - Крым, степная зона (Красногвардейский район, окрестности п. Октябрьское), II - Крым, горная зона (Бахчисарайский район, окрестности с. Севастьяновка) и III - Южный Урал (Баймакский район Республики Башкортостан). Содержание НЛ (\% от массы семян) для I, II, III составило $14.8 \%, 15.7 \%, 15.5 \%$ соответственно. Количество НЛ для всех образцов сравнимо и растения можно отнести к среднемасличным. Состав жирных кислот (ЖК) НЛ образцов представлен в табл. 1.

Из табл. 1 видно, что во всех образцах НЛ компонентный набор ЖК примерно одинаков (от 
14 в II до 16 в III) (табл. 1). Основными ЖК были: насыщенная пальмитиновая (16:0); моноеновая олеиновая (18:1) и полиненасыщенные эссенциальные жирные кислоты - линолевая (18:2), $\gamma$-линоленовая $(\gamma-18-3), \alpha$-линоленовая $(\alpha-18: 3)$ и стеаридоновая (18:4) кислоты. Общее количество ненасыщенных ЖК больше было в I и III, количество ПНЖК было примерно одинаково. Суммарное содержание насыщенных ЖК выше в II (табл. 1). Полученные нами данные по составу и содержанию ЖК близки к литературным [11-13].

Известно, что в рационе питания важное значение имеет количественное соотношения $\omega-6 / \omega-3$ ЖК [18]. По рекомендации ФАО ВОЗ, оптимальное суточное потребление $\omega-6 / \omega-3$ это 5-10:1 [19]. Полученные нами данные соответствуют рекомендуемым значениям.

Таблица 1

Состав жирных кислот нейтральных липидов семян Nonea pulla разных мест произрастания (\% от суммы ЖК)

\begin{tabular}{|c|c|c|c|}
\hline Кислота & I & II & III \\
\hline 12:0 & 2.57 & 1.17 & 0.14 \\
\hline $14: 0$ & 1.12 & 3.24 & 0.41 \\
\hline $15: 0$ & - & 3.01 & 1.61 \\
\hline 16:0 & 7.93 & 8.98 & 9.11 \\
\hline $16: 1$ & 0.54 & 0.65 & 0.52 \\
\hline 17:0 & 1.11 & 3.12 & 0.41 \\
\hline 18:0 & 3.21 & 2.02 & 3.14 \\
\hline $18: 1$ & 20.29 & 14.94 & 21.01 \\
\hline$\omega-6, \alpha-18: 2$ & 34.69 & 28.22 & 29.21 \\
\hline$\omega-6, \gamma-18: 3$ & 11.62 & 14.47 & 13.93 \\
\hline$\omega-3, \alpha-18: 3$ & 11.63 & 12.16 & 10.94 \\
\hline$\omega-3,18: 4$ & 3.55 & 5.98 & 3.73 \\
\hline 20:0 & 0.25 & 1.28 & 2.81 \\
\hline $20: 1$ & 0.22 & - & 0.32 \\
\hline 22:0 & 0.25 & 0.76 & 0.51 \\
\hline $22: 1$ & 1.02 & - & 2.20 \\
\hline$\Sigma_{\text {Насыщенных жК }}$ & 16.44 & 23.58 & 19.44 \\
\hline $\begin{array}{l}\Sigma_{\text {Ненасыщенных жк. }} \\
\text { В том числе }\end{array}$ & 83.56 & 76.42 & 81.86 \\
\hline $\begin{array}{l}\Sigma_{\text {пнжк }} \text { (эссенци- } \\
\text { альные) }\end{array}$ & 61.49 & 60.83 & 57.81 \\
\hline$\omega-6 / \omega-3$ & $3.0 / 1$ & $2.4 / 1$ & $2.9 / 1$ \\
\hline
\end{tabular}

Для дальнейшего более подробного исследования липидов были взяты семена Nonea pulla, произрастающей на Южном Урале (III). Выделеные полярные липиды (ПЛ) делили на глико- и фосфолипиды (ГЛ и ФЛ). Содержание (\% от массы семян): ПЛ $-1.17 \%$; ГЛ и ФЛ -0.5 и $0.7 \%$ (\% от массы ПЛ соответственно). Из НЛ, используя колоночную хроматографию, выделили основной класс нейтральных липидов - триацилглицериды (ТАГ), содержание которых составило $80 \%$ от массы НЛ.
Состав жирных кислот ТАГ и ПЛ представлен в табл. 2.

Состав ЖК ПЛ отличается от такого ТАГ значительным содержанием насыщенных ЖК (55.19\%) в основном за счет пальмитиновой (16:0) кислоты (33\%) (табл. 2). Содержание ненасыщенных ЖК и в т.ч. ПНЖК триацилглицеридов были близки к таковым жирных кислот НЛ образцов I, II, III из различных мест произрастания РФ.

Таблица 2

Состав жирных кислот триацилглцеридов и полярных липидов семян Nonea pulla, произрастающей на Южном Урале (\% от суммы ЖК)

\begin{tabular}{|c|c|c|}
\hline Кислота & ТАГ & ПЛ \\
\hline 12:0 & 0.22 & 1.50 \\
\hline 14:0 & 0.11 & 1.98 \\
\hline 15:0 & - & 3.84 \\
\hline $16: 0$ & 6.87 & 33.35 \\
\hline $16: 1$ & 0.29 & 1.44 \\
\hline 17:0 & - & 1.10 \\
\hline 18:0 & 2.76 & 11.56 \\
\hline 18:1 & 20.85 & 10.32 \\
\hline$\omega-6, \alpha-18: 2$ & 32.04 & 21.15 \\
\hline$\omega-6, \gamma-18: 3$ & 15.93 & 3.47 \\
\hline$\omega-3, \alpha-18: 3$ & 11.34 & 6.79 \\
\hline$\omega-3,18: 4$ & 3.82 & - \\
\hline $20: 0$ & 2.71 & 0.88 \\
\hline $20: 1$ & 0.30 & 0.65 \\
\hline $22: 0$ & 0.53 & 0.98 \\
\hline $22: 1$ & 2.23 & 0.99 \\
\hline $\bar{\Sigma}_{\text {Насыщенных жк }}$ & 13.20 & 55.19 \\
\hline $\begin{array}{l}\Sigma_{\text {Ненасыщенных жк. }} \\
\text { В том числе } \Sigma_{\text {пнжк }}\end{array}$ & $\begin{array}{l}83.56 \\
63.13\end{array}$ & $\begin{array}{l}44.81 \\
31.41\end{array}$ \\
\hline
\end{tabular}

Таким образом, семена Nonea pulla, произрастающей в различных климатических зонах РФ близки по составу и содержанию НЛ и жирных кислот, содержат значительные количества ненасыщенных, в т.ч. эссенциальных полиненасыщенных жирных кислот с соотношением $\omega-6 / \omega-3$, рекомендуемым ФАО ВОЗ, и могут служить дополнительным источником ПНЖК.

\section{Экспериментальная часть}

Состав ЖК определяли газожидкостной хроматографии анализом метиловых эфиров на хроматографе GC-2014 (Shimadzu) с капиллярной колонкой Omegawax TM 250 (30.0 м ×0.25 мм; Supelco), неподвижная фаза - полиэтиленгликоль L (0.25 мкм), температура колонки $205{ }^{\circ} \mathrm{C}$, температура испарителя $250{ }^{\circ} \mathrm{C}$, температура детектора $260{ }^{\circ} \mathrm{C}$, газ-носитель $\mathrm{He}$, скорость подачи газа 30 мл/мин.

Для выделения липидов воздушно-сухие семена измельчали на электрической мельнице до 
однородной массы, липиды извлекали экстракцией в аппарате Сокслета [20]: нейтральные липиды гексаном; полярные липиды - смесью хлороформа и метанола (2:1) по методу Блайя-Дайэра [21]. Для удаления спирторастворимых компонентов не липидной природы (углеводы, аминокислоты и т.д.) сгущенный экстракт ПЛ обрабатывали $0.1 \%$-ным раствором $\mathrm{NaCl}$.

Для очистки и идентификации НЛ использовали системы растворителей «гексан-диэтиловый эфир» с соотношением компонентов 9.5:0.5, 9:1, $8: 2,7: 3$ и 6:4 на пластинках ALUGRAM ${ }^{\mathrm{R}}$ SIL G или на пластинках «Silufol».

Для отделения глико- от фосфолипидов использовали тонкослойную хроматографию на силикагеле в ацетоне, высушенным над $\mathrm{K}_{2} \mathrm{CO}_{3}$. Опыты проводили на стеклянных пластинах $20 \times 20$ см с силикагелем марки MN-Kieselgel G (MachereyNagel GmbH \& Co.KG). Соединения на пластинках обнаруживали, помещая пластинку в камеру с кристаллическим иодом. Полосы проявившихся на пластинках соединений счищали в колбу и десорбировали с силикагеля смесью хлорофом-метанол. Количество каждого класса оценивали гравиметрически.

Щелочной гидролиз липидов осуществляли $10 \%$ $\mathrm{KOH}$ в $\mathrm{MeOH} \mathrm{(1:10)} \mathrm{при} 60^{\circ} \mathrm{C}$ в течение 30 мин [22].

Получение метиловых эфиров жирных кислот осуществляли раствором диазометана в диэтиловом эфире. Ход реакции контролировали с помощью TCX на пластинках «Silufol» в системе растворителей 2. Диазометан получали согласно [23]. Идентификацию липидов осуществляли по известным методикам [24-25].

Работа выполнена в рамках программы №AAАA-А20120012090026-9 госзадания с использованием оборудования ЦКП «Химия» УфИХ РАН и «Агидель» УФИЦ РАН.

\section{ЛИТЕРАТУРА}

1. Guil Guerrero J. L. Stearidonic acid (18:4n-3): Metabolism, nutritional importance, medical uses and natural sources // Eur. J. Lipid Sci. Technol, 2007. Vol. 109. No 12. Pp. 1226-1236.

2. Singh S. P., Zhou X. R., Liu Q., Stymne S., Green A. G. Metabolic engineering of new fatty acids in plants // Curr Opin Plant Biol.. 2005. Vol. 8. No. 2. Pp. 197-203.

3. Sardessai V. M. // Nutritional Role of Polyunsaturated Fatty Acids // J. Nutr. Biochem. 1992. Vol. 3. No 4. Pp. 154-166.

4. Guil-Guerrero J. L., García Maroto F. F. Giménez Giménez A. Fatty acid profiles from forty-nine plant species that are potential new sources of $\gamma$-linolenic acid // JAOCS. 2001. Vol. 78. No. 7. Pp. 677-683.

5. Charles R., Harper M. D., Terry A., Jacobson M. D.: The fatsof life. The role of omega 3 fatty acids in prevention of coronary heart disease // Arch Intern Med. 2001. Vol. 161. No. 18. Pp. 2185-2192.
6. WHO/EAO: Preparation and use of food-based dietary guidelines. WHO Technical Report Series, Rome (Italy). 1998. Pp. 880.

7. Swanson D. Block R. Mousa S.A. Omega-3 Fatty Acids EPA and DHA: Health Benefits Throughout Life // Adv Nutr. 2012. Vol. 3. No. 1. Pp. 1-7.

8. Deckelbaum R. J. Torrejón C. The omega-3 fatty acid nutritional landscape: health benefits and sources // J Nutr. 2012. Vol. 142. No. 5. Pp. S. 87-91.

9. Kidd P.M. Omega-3 DHA and EPA for cognition, behavior and mood: clinical fi ndings and structural-functional synergies with cell membrane phospholipids //Altern Med Rev. 2007. Vol. 12. No. 20. Pp. 7-27.

10. Яковлева Г. П., Блинова К. Ф. Лекарственное растительное сырье. Фармакогнозия, СпецЛит. СПб., 2004. С. 765.

11. Miller R. W., Earle F. R., Wolff I. A.. Search for new seed oils. XV. Oils of Boraginaceae // Lipids, 1968. Vol. 3. Pp. 43-45.

12. Guil-Guerrero J. L., Garcia-Maroto F., Vilches-Ferron M. A., Lopez-Alonso D. Gamma-linolenic acid from fourteen Boraginaceae species // Industrial Crops and Products. 2003. Vol. 18. No. 1. Pp. 85-93.

13. Öscan T. Analysis of the total oil and fatty acid composition of seeds of some Boraginaceae taxa from Turkey // Plant Syst Evol, 2008. No. 274. Pp. 143-153.

14. Yunusova S. G., Khatmulina L. I, Fedorov N. I., Ermolaeva N. F., Galkin E.G., Yunusov M. S. Polyunsaturated fatty acids from several plant species of the family Boraginaceae // Chem. Nat. Compd.. 2012. Vol. 48. No. 3. Pp. 361-366.

15. Yunusova S. G., Lyashenko S. S., Fedorov N. I., Denisenko O. N., Yunusov M. S.. Lipids and lipophilic constituents of Comfrey (Symphytum Officinale L.) seeds // Pharm. Chem. J. 2017. Vol. 50. No. 11. Pp. 728-731.

16. Yunusova S. G., Yunusov M. S., Fedorov N. I. Seed lipids from Pulmonaria obscura // Chem. Nat. Compd. 2018. Vol. 54. No. 4. Pp. 634-637.

17. Yunusova S. G., Lyashenko S. S, Fedorov N. I., Tleptserisheva Z. Yu., Denisenko O. N., Yunusov M. S. Seed lipids from Pulmonaria mollis growing in several RF climate zones // Chem. Nat. Compd. 2019. Vol. 55. No. 4. Pp. 597-601.

18. Simopoulos A. P.. Omega-3 fatty acids in health and disease and in growth and development // Am.J. Clin. Nutr. 1991. Vol. 54. No. 3. Pp. 438-463.

19. Rodriguez-Cruz A. R., Tovar. M. del Prado N. Torres. Molecular mechanisms of action and health benefits of polyunsaturated fatty acids // Revista de Investigacion Clinica. 2005. Vol. 57. No. 3. Pp. 457-472.

20. Руководство по методам исследования, технохимическому контролю и учету производства в масложировой промышленности. Л. ВНИИЖ. Ленинград. 1965. Т. 2. 152 с.

21. Bligh E. G.Dayer W. J. A rapid method for total lipid extraction and purification // Can.J.Biochem.Physiol. 1959. Vol. 37. Pp. 911-917.

22. Шталь Э. Хроматография в тонких слоях. Мир. М., 1965. C. 147.

23. Физер Л., Физер М. Реагенты для органического синтеза. Мир. М., 1970. 1. С. 242.

24. Karimova A. R., Yunusova S. G., Galkin E. G., Fedorov N. I., Yunusov M. S. Lipids and lipophilic components of Viburnum opullus fruits during maturation // Russ. Chem Bull. 2004. Vol. 53. No. 1. Pp. 245-250.

25. Kates M. Techniqies of lipidology. Isolation, analysis and identification of lipids. Amsterdam, London, New York. 1986. Pp. 464. 
DOI: 10.33184/bulletin-bsu-2020.2.7

\title{
FATTY ACIDS OF SEEDS NONEA PULLA DC GROWING IN THE TERRITORY OF THE RUSSIAN FEDERATION
}

\author{
(C) S. G. Yunusova ${ }^{1}$, S. S. Lyashenko ${ }^{2}$, K. V. Vedernikova ${ }^{3}$, \\ N. I. Fedorov ${ }^{4}$, Yu. O. Denisenko ${ }^{2}$, O. N. Denisenko ${ }^{2}$ \\ ${ }^{1}$ Ufa Institute of Chemistry, Ufa Federal Research Center of RAS \\ 71 Oktyabrya Avenue, 450054 Ufa, Republic of Bashkortostan, Russia. \\ ${ }^{2}$ Pyatigorsk Medical and Pharmaceutical Institute, \\ branch of the Volgograd State Medical University \\ 11 Kalinin Avenue, 357532 Pyatigorsk, Stavropol Krai, Russia. \\ ${ }^{3}$ Medical Academy named after S. I. Georgievsky, \\ Vernadsky Crimean Federal University \\ 5/7 Lenin Boulevard, 95006 Simferopol, Republic of Crimea, Russia. \\ ${ }^{4}$ Ufa Institute of Biology, Ufa Federal Research Center of RAS \\ 71 Oktyabrya Avenue, 450054 Ufa, Republic of Bashkortostan, Russia. \\ Phone: +7 (347) 2355839 . \\ *Email: msyunusov@anrb.ru
}

\begin{abstract}
Higher plants are producers of $\mathrm{C} 18$ polyunsaturated fatty acids (PUFA) - linoleic acid ( $\omega$-6 18:2 - 9,12-octadecadiene), $\gamma$-linolenic ( $\omega$-6 18:3 - 6,9,12-octadecatrienic), $\alpha$ linolenic ( $\omega-3$ 18:3 - 9,12,15-octadecatrienic) and stearidonic $(\omega-3$ 18:4 - 6,9,12,15octadecatetrienic), which as the final metabolites accumulate in plant tissues. In the human body, the final metabolites of these PUFA, depending on their structure, are various prostaglandins. PUFA are not synthesized in the human body, but assimilated from food. The lack of PUFA in daily nutrition can lead to the development of a wide range of diseases, such as cardiovascular, inflammatory processes, viral infections, some types of cancer, and autoimmune diseases. One of the plant sources of PUFA are plants of the Boraginaceae family. The authors studied 3 seed samples of Nonea pulla DC from different climatic zones of growth: I - from Crimea steppe zone, II - from Crimea mountain zone, and III from the Southern Urals. The content of neutral lipids (NL) (\%, of seed weight) for I, II, III was $14.8 \%, 15.7 \%$, and $15.5 \%$, respectively. The total number of unsaturated fatty acids (FA) was greater in I and III; the amount of PUFA for I, II, and III was approximately the same $(61.5 ; 60.8 ; 57.8$, respectively). The main FA were saturated palmitic (16:0), monoene oleic (18:1), and PUFA - $\alpha-18: 2, \gamma-18: 3, \alpha-18: 3$ and 18:4. Polar lipids (PL) were isolated from III, which were divided into glyco- (GL) and phospholipids (PhL). The content (\%, of seed weight) of PL was 1.17\%; GL and PhL -0.5 and $0.7 \%$ (\% of PL weight, respectively). Triacylglycerides (TAG) were isolated from NL. Their content was $80 \%$ of NL. The composition of PL differed from such TAGs by a significant amount of saturated FAs (55.2\%). The content of unsaturated FAs, including PUFA triacylglycerides, was close to those of NL fatty acids of samples I, II, and III.
\end{abstract}

Keywords: Nonea pulla, Boraginaceae, lipids, fatty acids.

Published in Russian. Do not hesitate to contact us at bulletin_bsu@mail.ru if you need translation of the article.

\section{REFERENCES}

1. Guil Guerrero J. L. Eur. J. Lipid Sci. Technol, 2007. Vol. 109. No 12. Pp. 1226-1236.

2. Singh S. P., Zhou X. R., Liu Q., Stymne S., Green A. G. Curr Opin Plant Biol.. 2005. Vol. 8. No. 2. Pp. 197-203.

3. Sardessai V. M. J. Nutr. Biochem. 1992. Vol. 3. No 4. Pp. 154-166.

4. Guil-Guerrero J. L., García Maroto F. F. JAOCS. 2001. Vol. 78. No. 7. Pp. 677-683.

5. Charles R., Harper M. D., Terry A., Jacobson M. D.: The fatsof life. The role of omega 3 fatty acids in prevention of coronary heart disease. Arch Intern Med. 2001. Vol. 161. No. 18. Pp. 2185-2192.

6. WHO/EAO: Preparation and use of food-based dietary guidelines. WHO Technical Report Series, Rome (Italy). 1998. Pp. 880.

7. Swanson D. Block R. Mousa S.A. Adv Nutr. 2012. Vol. 3. No. 1. Pp. 1-7. 
8. Deckelbaum R. J. Torrejón C. J Nutr. 2012. Vol. 142. No. 5. Pp. Pp. 87-91.

9. Kidd P.M.Altern Med Rev. 2007. Vol. 12. No. 20. Pp. 7-27.

10. Yakovleva G. P., Blinova K. F. Lekarstvennoe rastitel'noe syr'e [Medicinal plant raw materials]. Farmakognoziya, SpetsLit. Saint Petersburg, 2004. Pp. 765.

11. Miller R. W., Earle F. R., Wolff I. A.. Search for new seed oils. XV. Lipids, 1968. Vol. 3. Pp. 43-45.

12. Guil-Guerrero J. L., Garcia-Maroto F. Industrial Crops and Products. 2003. Vol. 18. No. 1. Pp. 85-93.

13. Öscan T. Plant Syst Evol, 2008. No. 274. Pp. 143-153.

14. Yunusova S. G., Khatmulina L. I, Fedorov N. I., Ermolaeva N. F., Galkin E.G., Yunusov M. S. Chem. Nat. Compd.. 2012. Vol. 48. No. 3. Pp. 361-366.

15. Yunusova S. G., Lyashenko S. S., Fedorov N. I., Denisenko O. N., Yunusov M. S.. Lipids and lipophilic constituents of Comfrey (Symphytum Officinale L.) seeds. Pharm. Chem. J. 2017. Vol. 50. No. 11. Pp. 728-731.

16. Yunusova S. G., Yunusov M. S., Fedorov N. I. Chem. Nat. Compd. 2018. Vol. 54. No. 4. Pp. 634-637.

17. Yunusova S. G., Lyashenko S. S, Fedorov N. I. Chem. Nat. Compd. 2019. Vol. 55. No. 4. Pp. 597-601.

18. Simopoulos A. P.. Omega-3 fatty acids in health and disease and in growth and development. Am.J. Clin. Nutr. 1991. Vol. 54. No. 3. Pp. 438-463.

19. Rodriguez-Cruz A. R., Tovar. M. del Prado N. Torres. Molecular mechanisms of action and health benefits of polyunsaturated fatty acids. Revista de Investigacion Clinica. 2005. Vol. 57. No. 3. Rr. 457-472.

20. Rukovodstvo po metodam issledovaniya, tekhnokhimicheskomu kontrolyu i uchetu proizvodstva $\mathrm{v}$ maslozhirovoi promyshlennosti [Guidelines for research methods, technochemical control and accounting of production in the fat and oil industry]. L. VNIIZh. Leningrad. 1965. Vol. 2.

21. Bligh E. G.Dayer W. J. Can.J.Biochem.Physiol. 1959. Vol. 37. Pp. 911-917.

22. Stahl E. Khromatografiya v tonkikh sloyakh [Thin layer chromatography]. Mir. Moscow, 1965. Pp. 147.

23. Fizer L., Fizer M. Reagenty dlya organicheskogo sinteza [Reagents for organic synthesis]. Mir. Moscow, 1970. 1. Pp. 242.

24. Karimova A. R., Yunusova S. G., Galkin E. G., Fedorov N. I., Yunusov M. S. Russ. Chem Bull. 2004. Vol. 53. No. 1. Pp. $245-250$.

25. Kates M. Techniqies of lipidology. Isolation, analysis and identification of lipids. Amsterdam, London, New York. 1986. Pp. 464.

Received 28.02.2020. 